\title{
Effects of Aerobic Training With No Caloric Restriction on Serum Resistin and Lipid Profile in Inactive Overweight Women
}

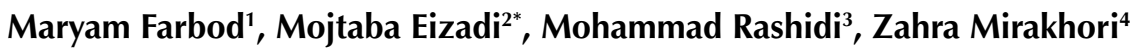 \\ ${ }^{1}$ Master of Science, Department of Physical Education and Sports Sciences, Parand Branch, Islamic Azad University, Tehran, \\ Iran. \\ ${ }^{2}$ Assistant Professor, Department of Exercise Physiology, Saveh Branch, Islamic Azad University, Saveh, Iran. \\ ${ }^{3}$ Assistant Professor, Department of Exercise Physiology, Semnan Branch, Islamic Azad University, Semnan, Iran. \\ ${ }^{4}$ Assistant Professor, Department of Physical Education and Sport Sciences, Amirkabir University of Technology, Tehran, \\ Iran.
}

\section{*Correspondence to} Mojtaba Eizadi; Department of Exercise Physiology, Saveh Branch, Islamic Azad University, Saveh, Iran. Tel: 09193551960

Fax: 086-42433007

Email: izadimojtaba2006@yahoo.com

Received May 8, 2017 Accepted May 8, 2020 Published online March 31, 2020

\begin{abstract}
Introduction: Obesity is a major risk factor for inflammation and cardiovascular diseases. We tried to assess whether 12 weeks of aerobic exercises affect serum resistin level and lipid profile in overweight females or not.

Methods: For this purpose, 32 non-trained adult females with the mean age of $38 \pm 7$ years old and body mass index (BMI) of $32 \pm 3 \mathrm{~kg} / \mathrm{m}^{2}$ were randomly assigned to aerobic exercise $(n=16)$ and control $(\mathrm{n}=16)$ groups. Twelve weeks of aerobic exercise program including 3 sessions weekly at $60-75 \%$ of maximum heart rate was considered. Fasting serum resistin level, lipid profile (total cholesterol [TC], low-density lipoprotein [LDL] and high-density lipoprotein [HDL] cholesterol, and triglyceride [TG]), and anthropometric indexes were measured and compared between the two groups before and after training.

Results: Serum resistin, lipid profile markers, and anthropometrical indexes were not significantly different at baseline between the two groups $(P>0.05)$. TG, TC, LDL, and serum resistin did not change significantly after the intervention in the exercise group $(P>0.05)$. However, a significant increase in HDL (exercise: $46.3 \pm 9.6$ vs. $51.4 \pm 8.5, P=0.011$; control: $45.8 \pm 7.9$ vs. $46.8 \pm 6.9$ $P=0.326$ ) and a significant decrease in LDL/HDL ratio (exercise: $2.94 \pm 0.12$ vs. $2.47 \pm 0.19$, $P=0.019$; control: $3.14 \pm 0.23$ vs. $3.18 \pm 0.63, P=0.265)$ were observed after the intervention. Other variables in the control group remained unchanged.

Conclusion: Aerobic exercises had no impacts on the inflammatory profile but could improve lipid profile with an emphasis on HDL in adult obese women.

Keywords: Aerobic training, Lipid profile, Obesity, Inflammation
\end{abstract}

Please cite this article as follows: Farbod M, Eizadi M, Rashidi M, Mirakhori Z. Effects of Aerobic Training With No Caloric Restriction on Serum Resistin and Lipid Profile in Inactive Overweight Women. Int J Basic Sci Med. 2020;5(1):915. doi: $10.34172 /$ ijbms.2020.03.

\section{Introduction}

Obesity and its associated illnesses have drawn the attention of many scholars in health sciences. The incidence of obesity and overweight is increasing in developed and developing countries. In addition to the psychological and social problems, obesity, especially abdominal obesity, is considered to be responsible for the incidence of many chronic and irreversible illnesses such as type II diabetes, liver diseases and cardiovascular and respiratory illnesses as well as some cancers. ${ }^{1,2}$ Although the main
\end{abstract}

molecular mechanisms of the relation between obesity and related diseases are not completely understood, based on scientific literature and research findings, it was concluded that increased adipose tissue mass is involved in inflammation associated with metabolic anomalies. During the last two decades, it has been shown that fatty tissue serves not only as the key foundation of fat stores in the body but also as an endocrine organ releasing many peptides or inflammatory and antiinflammatory mediators which play a

(C) 2020 The Author(s); Published by Zabol University of Medical Sciences. This is an open-access article distributed under the terms of the Creative Commons Attribution License (http://creativecommons.org/licenses/by/4.0), which permits unrestricted use, distribution, and reproduction in any medium, provided the original work is properly cited. 
central role in homeostasis such as insulin regulation or glucose and lipid metabolism. ${ }^{3}$ In this regard, numerous scientific resources have reported higher levels of inflammatory cytokines ${ }^{3,4}$ and lower levels of antiinflammatory cytokines ${ }^{5}$ in obese individuals compared to normal-weight individuals.

Among adipokines secreted by adipocytes, resistin is involved in regulating energy homeostasis and metabolism. ${ }^{6}$ In another definition, resistin is an inflammatory adipocytokine secreted by adipocytes. This inflammatory mediator belongs to a family of cysteine-rich carboxyl-terminal proteins called resistinlike molecules. ${ }^{7}$ This inflammatory adipocytokine was discovered in 2001 with a molecular weight of $12.5 \mathrm{kDa}{ }^{7}$ Besides adipose tissue, it is also released by pancreatic islets, muscles, and placenta in humans. ${ }^{8}$ Some studies have reported that increasing resistin expression results in an increase in serum-free fatty acid (FFA), muscle triglyceride (TG), and glucose intolerance. ${ }^{9}$ On the other hand, FFA and some other inflammatory cytokines such as tumor necrosis factor- $\alpha$ (TNF- $\alpha$ ) inhibit resistin expression. ${ }^{10,11}$ According to Lee et al, obese mouse models had higher resistin levels in comparison with their lean counterparts. ${ }^{12}$

Implementing appropriate strategies for improving the levels of inflammatory mediators in obesity has become the focus of scholars in health sciences. Among them, exercise and physical activities have always been discussed; although the findings regarding the response of inflammatory profile to exercises seem somewhat controversial in different populations. In this context, a study has recently reported that a weight loss program in the form of a 3-week dietary intervention, which was associated with more than $5 \%$ weight loss, significantly decreased resistin levels in severely obese women. ${ }^{13}$ Moreover, in a study by Park et al, 12 weeks of aerobic exercise significantly decreased resistin in overweight middle-aged women. ${ }^{14}$ Moreover, StavropoulosKalinoglou et al reported that compared to pre-training, 3 and 6 months of aerobic or resistance exercises led to a significant decreases in total cholesterol (TC), TG, and TC/high-density lipoprotein (HDL) and increase in HDL in patients with rheumatoid arthritis. ${ }^{15}$ Nevertheless, some other investigations have reported unchanged resistin levels in response to short and long-term exercise training. For example, in a study by Giannopoulou et al, there were no statistically significant alterations following 14 weeks of aerobic exercise in serum resistin and TNF- $\alpha$ in postmenopausal women with type 2 diabetes. ${ }^{16}$ Additionally, Kelly et al reported that 8 weeks of aerobic training did not significantly influence adipokines or oxidative stress markers in overweight children. ${ }^{17}$ In another investigation by Colombo et al, 12 weeks of aerobic exercise triggered no changes in TC, TG, and low-density lipoprotein (LDL) cholesterol in patients with metabolic syndrome, however, HDL cholesterol level improved. ${ }^{18}$
Based on these findings, there is uncertainty regarding the effect of exercises on the levels of resistin and other adipokines. Due to the conflicting findings reported in previous studies as well as limited investigations on the impacts of exercise on resistin levels in obese females, this study tried to determine the impact of three months of aerobic exercise on serum resistin levels as well as lipid markers in sedentary overweight females.

\section{Materials and Methods}

Thirty-two non-trained adult females volunteered to participate in this research (the mean age of $38 \pm 7$ years old, the maximum age of 41 , and a body mass index (BMI) of $32 \pm 3 \mathrm{~kg} / \mathrm{m}^{2}$. By simple randomization, they were classified into exercise (aerobic training) $(n=16)$ and control $(n=16)$ groups.

\section{Inclusion Criteria}

All participants were physically inactive $\left(\mathrm{VO}_{2 \max } \leq 27\right.$ $\mathrm{ml} / \mathrm{kg}^{-1} / \mathrm{min}^{-1}$ ), non-smoker, and non-alcoholic. They were excluded from the study if they had regular exercise trainings in the last 6 months. The participants had no serious health problems like diabetes (glucose $<126 \mathrm{mg}$ / $\mathrm{dL}$ ) and took no supplements of any kind. They provided informed consent before entering the study.

\section{Anthropometric Measurements}

Anthropometric measurements were done for both groups, including height, body fat (\%), weight, and circumference measurements before and after the exercise. Height measurement was done without shoes, and on the same day, body weight was also measured. In standing position, abdominal obesity was determined. The waist circumference was measured using a flexible non-extensible plastic tape. The tape was placed above the iliac crest parallel to the ground, with the participant standing straight with the abdomen relaxed, feet together, and arms along the body. At the greatest protrusion of the gluteal muscles with underwear, hip girth was measured. Body fat and visceral fat percentages were measured using bioelectrical impedance method (Omron Body Fat Analyzer, BF 508, Finland). The same researcher did all the measurements.

\section{Exercise Program}

The exercise group accomplished a 12-week aerobic training intervention (Table 1). It involved a warm-up followed by a $30-45$ minute aerobic workout at an intensity of $60 \%-75 \%$ of maximum heart rate $\left(\mathrm{HR}_{\max }\right)$ accompanied by 10 -minute cooling-down. In each session, the major exercise was running at the stated intensity. ${ }^{19}$ The heart rate for determining the intensity of exercise was estimated by counting heartbeats using polar telemetry. The exercise intensity started below $60 \% \mathrm{HR}_{\max }$, which was gradually risen to $75 \%$ at subsequent sessions. In every session, active rest was assumed as walking between the running 
Table 1. Time and Intensity of Exercise (Running) in Aerobic Training Intervention

\begin{tabular}{lccc}
\hline $\begin{array}{l}\text { Intervention } \\
\text { Duration (wk) }\end{array}$ & $\begin{array}{c}\text { Running Time } \\
(\mathbf{m i n})\end{array}$ & $\begin{array}{c}\text { Rest Between Sets } \\
(\mathbf{m i n})\end{array}$ & $\begin{array}{c}\text { Exercise Intensity } \\
(\% \text { HRmax })\end{array}$ \\
\hline 1 & $2 \times 5^{*}$ & 3 & $<60$ \\
2 & $2 \times 5$ & 3 & $60-65$ \\
3 & $3 \times 5$ & 3 & $60-65$ \\
4 & $3 \times 5$ & 3 & $65-70$ \\
5 & $2 \times 10$ & 3 & $65-70$ \\
6 & $2 \times 12$ & 5 & $65-70$ \\
$7-8$ & $2 \times 12$ & 5 & $70-75$ \\
$9-12$ & $2 \times 15$ & 5 & $70-75$ \\
$2 \times 5^{*}$ represent 2 sessions of 5-minute duration.
\end{tabular}

sets. During menstrual cycles, exercise intensity declined by $5 \%$ for every participant..$^{20}$ The subjects were told to have their daily diet during the investigation. In addition, the control group maintained their daily activities.

\section{Laboratory Analyses}

Blood samples were collected before and after training (48 hours following the last exercise session) to measure biochemical markers after fasting overnight between 8 AM to 9 AM. Before sampling, they were told not to do any intense physical activity for 48 hours. Serum samples were separated immediately and kept at $-80^{\circ} \mathrm{C}$. The serum was used to measure triglyceride, LDL-C, TC, and HDL-C as lipid profile markers by enzymatic methods (Randox direct kits), employing Cobas Mira auto-analyzer (Germany). ELISA method (ELISA for quantitatively detecting human resistin, Biovendor Laboratorial, Czech Republic) was also employed for measuring serum resistin levels. The intra-assay and inter-assay coefficient of variation of resistin were $2.8 \%$ and $5.1 \%$ respectively and sensitivity of the method was $0.033 \mathrm{ng} / \mathrm{mL}$.

\section{Statistical Analysis}

SPSS version 15.0 (SPSS Inc., IL, USA) was used to analyze the data. To evaluate the normal distribution of data, the Kolmogorov-Smirnov test was employed. Student's paired samples $t$ test was used to determine the differences between study groups. The data obtained before and after the training were compared using independent samples $t$ test to indicate the effect of the training program on independent variables (i.e., TC, LDL, resistin, TG, and HDL). A $P$ value of $<0.05$ was considered statistically significant.

\section{Results}

Data were reported as mean \pm SD. The control and experimental groups were not significantly different regarding the pre-test anthropometric indices $(P>0.05)$. The body fat percentage, BMI, and abdominal obesity after training significantly decreased in the experimental group $(P<0.05)$. All variables remained unchanged in the control group $(P>0.05)$ (Table 2$)$.

LDL $(P=0.562)$, TG $(P=0.465)$, serum resistin $(P=0.323)$, TC $(P=0.811)$, and HDL $(P=0.524)$ were not different at baseline between two groups. The influence of aerobic exercise on lipid profile markers and resistin was the focus of the current research. No differences were seen in post-intervention results of resistin $(P=0.111)$, TG $(P=0.132)$, TC $(P=0.124)$, and LDL $(P=0.265)$ between the groups. However, significant variations were

Table 2. Mean and SD of Anthropometric Characteristics of the Target Groups

\begin{tabular}{|c|c|c|c|c|c|c|}
\hline \multirow{2}{*}{ Variables } & \multicolumn{2}{|c|}{ Exercise Group } & \multirow{2}{*}{$P$ Value } & \multicolumn{2}{|c|}{ Control Group } & \multirow{2}{*}{$P$ Value } \\
\hline & Pre-training & Post-training & & Pre-training & Post-training & \\
\hline Age (y) & $38.4 \pm 7.65$ & $38.4 \pm 7.65$ & - & $37.3 \pm 2.39$ & $37.3 \pm 2.39$ & - \\
\hline Height (cm) & $162 \pm 4.86$ & $162 \pm 4.86$ & - & $161 \pm 4.66$ & $161 \pm 4.66$ & - \\
\hline Weight (kg) & $83 \pm 8.45$ & $81 \pm 8.46$ & 0.011 & $83.7 \pm 4.81$ & $83.6 \pm 4.71$ & 0.221 \\
\hline $\mathrm{AC}(\mathrm{cm})$ & $107 \pm 7.4$ & $103 \pm 8$ & 0.029 & $108 \pm 8$ & $108 \pm 7$ & 0.323 \\
\hline $\mathrm{HC}(\mathrm{cm})$ & $104 \pm 11$ & $101 \pm 9$ & 0.031 & $105 \pm 10$ & $106 \pm 11$ & 0.412 \\
\hline $\mathrm{BMI}\left(\mathrm{kg} / \mathrm{m}^{2}\right)$ & $32.1 \pm 2.76$ & $31.6 \pm 2.80$ & 0.017 & $31.73 \pm 1.58$ & $31.71 \pm 1.57$ & 0.325 \\
\hline $\mathrm{BF}(\%)$ & $44.7 \pm 4.55$ & $43 \pm 4.54$ & 0.023 & $44.1 \pm 2.95$ & $43.3 \pm 2.57$ & 0.632 \\
\hline
\end{tabular}

AC: abdominal circumference; HC: hip circumference; BMI: body mass index, BF: body fat percentage

Table 3. Mean and SD of Biochemical Markers of the Target Groups

\begin{tabular}{|c|c|c|c|c|c|c|}
\hline \multirow{2}{*}{ Variables } & \multicolumn{2}{|c|}{ Exercise Group } & \multirow{2}{*}{$P$ Value } & \multicolumn{2}{|c|}{ Control Group } & \multirow{2}{*}{$P$ Value } \\
\hline & Pre-training & Post-training & & Pre-training & Post-training & \\
\hline Resistin (ng/ml) & $2.30 \pm 1.07$ & $2.33 \pm 1.06$ & 0.223 & $2.25 \pm 0.96$ & $2.31 \pm 0.85$ & 0.196 \\
\hline $\mathrm{TG}(\mathrm{mg} / \mathrm{dL})$ & $173 \pm 41$ & $168 \pm 39$ & 0.119 & $181 \pm 51$ & $179 \pm 43$ & 0.426 \\
\hline TC (mg/dL) & $211 \pm 66$ & $199 \pm 52$ & 0.323 & $198 \pm 43$ & $208 \pm 51$ & 0.367 \\
\hline LDL (mg/dL) & $136 \pm 29$ & $127 \pm 33$ & 0.412 & $144 \pm 33$ & $149 \pm 46$ & 0.513 \\
\hline $\mathrm{HDL}(\mathrm{mg} / \mathrm{dL})$ & $46.3 \pm 9.6$ & $51.4 \pm 8.5$ & 0.011 & $45.8 \pm 7.9$ & $46.8 \pm 6.9$ & 0.326 \\
\hline LDL/HDL & $2.94 \pm 0.12$ & $2.47 \pm 0.19$ & 0.021 & $3.14 \pm 0.23$ & $3.18 \pm 0.63$ & 0.265 \\
\hline
\end{tabular}

TG: triglyceride; TC: total cholesterol; HDL: high density lipoprotein cholesterol; LDL: low density lipoprotein cholestero 
found in the post-test results of LDL/HDL $(P=0.019)$ and HDL $(P=0.014)$ between the control and exercise groups. Moreover, aerobic exercise significantly increased HDLcholesterol compared to the control group. Moreover, the ratio of LDL to HDL (LDL/HDL) significantly declined in the exercise group only (Table 3 ).

\section{Discussion}

An inactive lifestyle is a risk factor for insulin resistance, visceral fat accumulation, type 2 diabetes, and cardiovascular diseases. The positive effects of moderateintensity exercise on the metabolic profile are well known. A contradiction exists in the responses of the inflammatory markers or metabolic profile to various exercise trainings in different populations. The findings of the present research revealed that 12 weeks of aerobic training did not change serum resistin levels in adult obese women with a sedentary lifestyle. Furthermore, the present study found no changes in TG, cholesterol, and LDL in obese women. HDL levels, however, increased significantly after training. Earlier investigations have reported higher baseline levels of resistin or other inflammatory mediators in obese individuals, ${ }^{21,22}$ On the other hand, apart from the type of training program, other factors such inflammatory adipokines may also affect resistin levels.

Resistin is a $12.5-\mathrm{KD}$ adipokine which is secreted by adipocytes, pancreas, and other active tissues. ${ }^{23}$ Resistin causes peripheral resistance to insulin and the emergence of type 2 diabetes. ${ }^{24}$ Clinical studies show that resistin raises the expression of hepatic gluconeogenesis enzymes by inhibiting the stimulation of AMP-activated protein kinase, reducing glycogen stores and insulin resistance and increasing the release of hepatic glucose. ${ }^{25}$ A study reported a significant correlation between serum resistin and blood lipids such as total cholesterol, TG, and LDL in women with diabetes. ${ }^{26}$ However, some other investigations did not report any correlation between serum resistin and levels of glucose, insulin, and BMI in obese women..$^{27}$ Silha et al did not show any correlation between BMI and resistin in lean and obese subjects. ${ }^{28}$

Scholars have found that levels of inflammation mediators fluctuate in response to workout activities. In some investigations, resistin decreased in diabetic or obese subjects in response to 2 and 3 months of aerobic exercises. $^{29-31}$ In another study, 12 weeks of exercise significantly reduced leptin, resistin, visfatin, triglycerides, cholesterol, and LDL and increased HDL in two groups of diabetic and obese children. ${ }^{32}$ Moreover, 24 weeks of exercise in the form of fast running on treadmill ( 5 sessions of 1 hour per week) reduced weight and abdominal circumference which was associated with a significant reduction in TC, TG, LDL, and glucose, and caused an increase in HDL in metabolic syndrome patients. ${ }^{33}$ In contrast, some researchers have denied the positive effects of training on lipid profile and inflammatory markers. ${ }^{34}$ In a study, 6 months of aerobic exercise did not change pro-inflammatory cytokines interleukin-6 (IL-6), C-reactive protein (CRP), and TNF- $\alpha$ in overweight or obese women. ${ }^{35}$ In another study, 12 weeks of moderateintensity aerobic training did not affect cardiovascular markers including TG, cholesterol, and HDL in overweight women with metabolic syndrome; nevertheless, serum CRP levels decreased significantly. ${ }^{36}$ Yet another study reported no alternations in cardiovascular risk factors as a reaction to the long-term training program. ${ }^{37}$

Obese people often have higher lipid levels. ${ }^{38}$ Some scholars have pointed out that by an average weight loss, obese people can experience significant improvement in metabolic risk factors for obesity-related diseases, particularly type 2 diabetes and cardiovascular diseases. ${ }^{18,38}$ However, some studies have reported no variations in serum levels of cardiovascular risk factors or lipid profile markers such as TG, LDL, TC, and HDL after a long training period in obese women. ${ }^{39}$ Moreover, in spite of lower levels of inflammatory cytokines such as CRP in some studies, a slight reduction was observed in cardiovascular risk factors in reaction to a weight loss program in overweight subjects. ${ }^{40}$ Furthermore, serum TG and LDL levels decreased significantly, followed by $11 \mathrm{~kg}$ weight loss after a year-long weight loss program. ${ }^{41}$ Jorje et $\mathrm{al}^{42}$ and Tan et $\mathrm{al}^{43}$ found that aerobic training was correlated with improvement in the lipid profile. Januszek et $\mathrm{al}^{36}$ found that these variables remained unchanged in response to aerobic exercises. Hosseini et $\mathrm{al}^{44}$ showed that 8 weeks of resistance and aerobic exercise did not change lipid profile markers in obese girls. In a study by Thomas et al, neither of two 11-week training programs (one in form of intermittent runs and another in the form of continuous aerobic exercise) affected plasma HDL and TG levels in male students. ${ }^{45}$ However, Altena et al found that a short training period in the form of 4 weeks of continuous and interval runs (five sessions a week) decreased LDL and TC and increased plasma HDL. ${ }^{46}$

Some studies have attributed improved cardiovascular risk factors or inflammatory profile to weight loss or body fat percentage in reaction to an exercise program. Therefore, 12 months of exercise in the absence of weight loss did not influence the levels of inflammatory and anti-inflammatory cytokines and cardiovascular risk factors. ${ }^{47}$ The findings of a 12 -week weight loss program (exercise and diet change) by Jung et $\mathrm{al}^{48}$ revealed that a weight loss of more than $5 \%$ was correlated with decreased resistin level and improved insulin resistance. ${ }^{49}$ In this study, despite a significant decrease in body weight and other anthropometric parameters as a result of 12 weeks of exercise in obese women, cardiovascular risk factors and serum resistin did not change significantly, which is controversial. However, in a recent study, serum resistin significantly declined in obese patients in reaction to 12 months of aerobic training. ${ }^{14}$ In a recent study, serum resistin significantly decreased in obese subjects in 
response to 12 months of exercise. ${ }^{14}$ Giannopoulou et al showed that serum resistin remained unchanged after 14 weeks of moderate-intensity aerobic exercise in diabetic women. ${ }^{16}$ Eight weeks of aerobic training did not influence serum resistin in overweight children. ${ }^{17}$ The lack of change in serum resistin in the current study may be justified by the fact that other studies found a minimum (10\%) of weight loss necessary for improvement in metabolic profile or inflammatory profile in obese populations. ${ }^{50}$ Although there was a significant decline in weight and body fat percentage in the current research, its value was far less than $5 \%$ in comparison to the levels prior to the exercise program.

\section{Limitations}

Ignoring additional parameters such as adiponectin, leptin, TNF- $\alpha$, and some interleukins is one of the limitations of the present research. The absence of diet control and lack of cardiovascular fitness are the other limitations of this study.

\section{Conclusion}

Our study showed that a 3-month aerobic training did not affect serum resistin levels in sedentary obese women. However, considering the improved HDL level and LDL/HDL ratio, it is concluded that aerobic training can improve cardiovascular function in the mentioned population. According to the findings of this study and the previous findings, no certain mechanism can be provided by which the prolonged exercise can influence resistin levels or other adipokines, while seemingly the type and style of training programs and target populations are among the most important elements involved in obtaining contradictory results.

\section{Ethical Approval}

The Ethics Committee of Islamic Azad University approved our study (Ethical Approval Number: 31547).

\section{Conflict of Interest Disclosure}

None.

\section{Authors' Contribution}

All authors had equal role in design, work, statistical analysis and manuscript writing.

\section{Acknowledgments}

We would like to thank all people who participated in this study as well as the Research Deputy of Islamic Azad University for financial support and assistance.

\section{References}

1. Codoñer-Franch P, Tavárez-Alonso S, Porcar-Almela M, Navarro-Solera M, Arilla-Codoñer Á, Alonso-Iglesias E. Plasma resistin levels are associated with homocysteine, endothelial activation, and nitrosative stress in obese youths. Clin Biochem. 2014;47(1-2):44-48. doi:10.1016/j. clinbiochem.2013.10.021

2. Hribal ML, Fiorentino TV, Sesti G. Role of C reactive protein (CRP) in leptin resistance. Curr Pharm Des. 2014;20(4):609-615. doi:10.2174/13816128113199990016

3. Dahlén EM, Tengblad A, Länne $\mathrm{T}$, et al. Abdominal obesity and low-grade systemic inflammation as markers of subclinical organ damage in type 2 diabetes. Diabetes Metab. 2014;40(1):76-81. doi:10.1016/j.diabet.2013.10.006

4. Caslin HL, Franco RL, Crabb EB, Huang CJ, Bowen MK, Acevedo EO. The effect of obesity on inflammatory cytokine and leptin production following acute mental stress. Psychophysiology. 2016;53(2):151-158. doi:10.1111/ psyp. 12568

5. Sanip Z, Ariffin FD, Al-Tahami BA, Sulaiman WA, Rasool $\mathrm{AH}$. Obesity indices and metabolic markers are related to hs-CRP and adiponectin levels in overweight and obese females. Obes Res Clin Pract. 2013;7(4):e315-320. doi:10.1016/j.orcp.2012.05.002

6. Rashidlamir H, Gholamian S, Ebrahimi Atri A. Effect of regular aerobic training on resistin gene expression in active young females. Sport Physiology. 2013;5(18):95-106. [Persian].

7. Steppan CM, Bailey ST, Bhat S, et al. The hormone resistin links obesity to diabetes. Nature. 2001;409(6818):307-312. doi: $10.1038 / 35053000$

8. Reilly MP, Lehrke M, Wolfe ML, Rohatgi A, Lazar MA, Rader DJ. Resistin is an inflammatory marker of atherosclerosis in humans. Circulation. 2005;111(7):932939. doi:10.1161/01.cir.0000155620.10387.43

9. Luo R, Li X, Zhao Y. Serum resistin and adiponectin concentrations in patients with overweight and obesity. Journal of Medical Colleges of PLA. 2007;22(3):160-164. doi:10.1016/S1000-1948(07)60034-3

10. Delhanty PJ, Mesotten D, McDougall F, Baxter RC. Growth hormone rapidly induces resistin gene expression in white adipose tissue of spontaneous dwarf (SDR) rats. Endocrinology. 2002;143(6):2445-2448. doi:10.1210/ endo.143.6.8947

11. Yang YM, Xu ZR, Wu LJ, Huang WD. Study of Resistin gene expression in peripheral blood mononuclear cell and its gene polymorphism in a small range population. J Zhejiang Univ Sci B. 2007;8(2):132-135. doi:10.1631/ jzus.2007.B0132

12. Lee JH, Bullen JW Jr, Stoyneva VL, Mantzoros CS. Circulating resistin in lean, obese, and insulin-resistant mouse models: lack of association with insulinemia and glycemia. Am J Physiol Endocrinol Metab. 2005;288(3):E625-632. doi:10.1152/ajpendo.00184.2004

13. Varady KA, Tussing L, Bhutani S, Braunschweig CL. Degree of weight loss required to improve adipokine concentrations and decrease fat cell size in severely obese women. Metabolism. 2009;58(8):1096-1101. doi:10.1016/j. metabol.2009.04.010

14. Park SH, Han TK, Ann ES, Yoon ES, Kim B, Kang HS, Effect of training intensity on subcutaneous adipose leptin, adiponectin, interleukin 6, and tumor necrosis factor mRNA expression in middle-aged women. FASEB J. 2008;22(S2):118. doi:10.1096/fasebj.22.2_supplement.118 
15. Stavropoulos-Kalinoglou A, Metsios GS, Veldhuijzen van Zanten JJ, Nightingale P, Kitas GD, Koutedakis Y. Individualised aerobic and resistance exercise training improves cardiorespiratory fitness and reduces cardiovascular risk in patients with rheumatoid arthritis. Ann Rheum Dis. 2013;72(11):1819-1825. doi:10.1136/ annrheumdis-2012-202075

16. Giannopoulou I, Fernhall B, Carhart R, et al. Effects of diet and/or exercise on the adipocytokine and inflammatory cytokine levels of postmenopausal women with type 2 diabetes. Metabolism. 2005;54(7):866-875. doi:10.1016/j. metabol.2005.01.033

17. Kelly AS, Steinberger J, Olson TP, Dengel DR. In the absence of weight loss, exercise training does not improve adipokines or oxidative stress in overweight children. Metabolism. 2007;56(7):1005-1009. doi:10.1016/j. metabol.2007.03.009

18. Colombo CM, de Macedo RM, Fernandes-Silva MM, et al. Short-term effects of moderate intensity physical activity in patients with metabolic syndrome. Einstein (Sao Paulo). 2013;11(3):324-330. doi:10.1590/s167945082013000300011

19. Eizadi M, Sokhanguei Y, Eghdami A, Banaeifar A. Effect of aerobic exercise on pancreas beta-cells function in adult obese males. Journal of Birjand University of Medical Sciences. 2014;21(2):203-210. [Persian].

20. Mohammadi B, Azamian Jazi A, Faramarzi M, Fathollahi Shourabeh F. The effect of aerobic exercise training and detraining on some of the menstrual disorders in non-athlete students in Lorestan Universities. Gonabad University of Medical Sciences. 2012;18(3):5-13. [Persian].

21. Asterholm IW, Rutkowski JM, Fujikawa T, et al. Elevated resistin levels induce central leptin resistance and increased atherosclerotic progression in mice. Diabetologia. 2014;57(6):1209-1218. doi:10.1007/s00125-014-3210-3

22. Hivert MF, Sullivan LM, Fox CS, et al. Associations of adiponectin, resistin, and tumor necrosis factoralpha with insulin resistance. J Clin Endocrinol Metab. 2008;93(8):3165-3172. doi:10.1210/jc.2008-0425

23. Schwartz DR, Lazar MA. Human resistin: found in translation from mouse to man. Trends Endocrinol Metab. 2011;22(7):259-265. doi:10.1016/j.tem.2011.03.005

24. Carrascosa JM, Andrés A, Ros M, et al. Development of insulin resistance during aging: involvement of central processes and role of adipokines. Curr Protein Pept Sci. 2011;12(4):305-315. doi:10.2174/138920311795906655

25. Li FP, He J, Li ZZ, Luo ZF, Yan L, Li Y. Effects of resistin expression on glucose metabolism and hepatic insulin resistance. Endocrine. 2009;35(2):243-251. doi:10.1007/ s12020-009-9148-4

26. Zare Z, Meshkibaf M, Hamaitkhah V, Ranjbaran R, Takhshid M. Positive correlation of resistin with blood lipids in gestational diabetes. Journal of Fasa University of Medical Sciences. 2014;3(4):330-335. [Persian].

27. Janowska J, Zahorska-Markiewicz B, OlszaneckaGlinianowicz M. Relationship between serum resistin concentration and proinflammatory cytokines in obese women with impaired and normal glucose tolerance. Metabolism. 2006;55(11):1495-1499. doi:10.1016/j. metabol.2006.06.020
28. Silha JV, Krsek M, Skrha JV, Sucharda P, Nyomba BL, Murphy LJ. Plasma resistin, adiponectin and leptin levels in lean and obese subjects: correlations with insulin resistance. Eur J Endocrinol. 2003;149(4):331-335. doi:10.1530/ eje.0.1490331

29. Brunelli DT, Chacon-Mikahil MP, Gáspari AF, et al. Combined training reduces subclinical inflammation in obese middle-age men. Med Sci Sports Exerc. 2015;47(10):2207-2215. doi:10.1249/ mss.0000000000000658

30. Wenning P, Kreutz T, Schmidt A, et al. Endurance exercise alters cellular immune status and resistin concentrations in men suffering from non-insulin-dependent type 2 diabetes. Exp Clin Endocrinol Diabetes. 2013;121(8):475482. doi:10.1055/s-0033-1343395

31. Bai Y, Zhang J, Jiang S, et al. [Effects of the body fat mass and blood sugar and plasma resistin to slim exercise prescription for overweight and obesity students]. Wei Sheng Yan Jiu. 2013;42(4):538-542, 549.

32. Lee SS, Kang S. Effects of regular exercise on obesity and type 2 diabete mellitus in Korean children: improvements glycemic control and serum adipokines level. J Phys Ther Sci. 2015;27(6):1903-1907. doi:10.1589/jpts.27.1903

33. Di Raimondo $\mathrm{D}$, Tuttolomondo $\mathrm{A}$, Buttà $\mathrm{C}$, et al. Metabolic and anti-inflammatory effects of a home-based programme of aerobic physical exercise. Int J Clin Pract. 2013;67(12):1247-1253. doi:10.1111/ijcp.12269

34. Lopes WA, Leite N, da Silva LR, et al. Effects of 12 weeks of combined training without caloric restriction on inflammatory markers in overweight girls. J Sports Sci. 2016;34(20):1902-1912. doi:10.1080/02640414.2016.1142 107

35. Lakka TA, Lakka HM, Rankinen T, et al. Effect of exercise training on plasma levels of C-reactive protein in healthy adults: the HERITAGE Family Study. Eur Heart J. 2005;26(19):2018-2025. doi:10.1093/eurheartj/ehi394

36. Januszek R, Mika P, Konik A, Petriczek T, Nowobilski R, Niżankowski R. Effect of treadmill training on endothelial function and walking abilities in patients with peripheral arterial disease. J Cardiol. 2014;64(2):145-151. doi:10.1016/j.jjcc.2013.12.002

37. Gregg EW, Cheng YJ, Cadwell BL, et al. Secular trends in cardiovascular disease risk factors according to body mass index in US adults. JAMA. 2005;293(15):1868-1874. doi:10.1001/jama.293.15.1868

38. Laddu D, Dow C, Hingle M, Thomson C, Going S. A review of evidence-based strategies to treat obesity in adults. Nutr Clin Pract. 2011;26(5):512-525. doi: $10.1177 / 0884533611418335$

39. Rock CL, Flatt SW, Sherwood NE, Karanja N, Pakiz B, Thomson CA. Effect of a free prepared meal and incentivized weight loss program on weight loss and weight loss maintenance in obese and overweight women: a randomized controlled trial. JAMA. 2010;304(16):18031810. doi:10.1001/jama.2010.1503

40. Camhi SM, Stefanick ML, Ridker PM, Young DR. Changes in C-reactive protein from low-fat diet and/or physical activity in men and women with and without metabolic syndrome. Metabolism. 2010;59(1):54-61. doi:10.1016/j. metabol.2009.07.008 
41. Foster GD, Wyatt HR, Hill JO, et al. Weight and metabolic outcomes after 2 years on a low-carbohydrate versus low-fat diet: a randomized trial. Ann Intern Med. 2010;153(3):147157. doi:10.7326/0003-4819-153-3-201008030-00005

42. Jorge ML, de Oliveira VN, Resende NM, et al. The effects of aerobic, resistance, and combined exercise on metabolic control, inflammatory markers, adipocytokines, and muscle insulin signaling in patients with type 2 diabetes mellitus. Metabolism. 2011;60(9):1244-1252. doi:10.1016/j. metabol.2011.01.006

43. Tan S, Wang J, Cao L, Guo Z, Wang Y. Positive effect of exercise training at maximal fat oxidation intensity on body composition and lipid metabolism in overweight middleaged women. Clin Physiol Funct Imaging. 2016;36(3):225230. doi:10.1111/cpf.12217

44. Hosseini Kakhk S, Azarnive M, Hamedinia M. The Effect of Resistance Training, Aerobic Training and Detraining on the Lipid Profile and CRP in Obese Girls. Journal of Sabzevar University of Medical Sciences. 2011;18(3):188197. [Persian].

45. Thomas TR, Adeniran SB, Iltis PW, Aquiar CA, Albers JJ. Effects of interval and continuous running on HDLcholesterol, apoproteins A-1 and B, and LCAT. Can J Appl Sport Sci. 1985;10(1):52-59.
46. Altena TS, Michaelson JL, Ball SD, Guilford BL, Thomas TR. Lipoprotein subfraction changes after continuous or intermittent exercise training. Med Sci Sports Exerc. 2006;38(2):367-372. doi:10.1249/01. mss.0000185088.33669.fd

47. Bouchonville M, Armamento-Villareal R, Shah K, et al. Weight loss, exercise or both and cardiometabolic risk factors in obese older adults: results of a randomized controlled trial. Int J Obes (Lond). 2014;38(3):423-431. doi:10.1038/ijo.2013.122

48. Jung SH, Park HS, Kim KS, et al. Effect of weight loss on some serum cytokines in human obesity: increase in IL10 after weight loss. J Nutr Biochem. 2008;19(6):371-375. doi:10.1016/j.jnutbio.2007.05.007

49. Valsamakis G, McTernan PG, Chetty R, et al. Modest weight loss and reduction in waist circumference after medical treatment are associated with favorable changes in serum adipocytokines. Metabolism. 2004;53(4):430-434. doi:10.1016/j.metabol.2003.11.022

50. Dow CA, Thomson CA, Flatt SW, Sherwood NE, Pakiz B, Rock CL. Predictors of improvement in cardiometabolic risk factors with weight loss in women. J Am Heart Assoc. 2013;2(6):e000152. doi:10.1161/jaha.113.000152 